\title{
Moving up the savings hierarchy: examining savings motives of older Malay Muslim
}

\begin{abstract}
Continuation ratio analysis of data from the 2004 Economic and Financial Aspects of Aging in Malaysia was conducted to assess likelihood of Malay Muslims aged 55-75 moving up in a hierarchical model of savings motives. Results indicate that more than half of older Malay Muslim has no savings. Many are barely surviving economically. Family size, educational level, health perception, income quintiles and income adequacy were important predictors of advancing from a lower level to a higher level in the savings motive hierarchy. Saving for Hajj was an important self-actualization savings motive.
\end{abstract}

Keyword: Hierarchy of savings; Saving motives; Older Malay; Malaysia 